\title{
Capitulum and rosette leaf avoidance from grazing by large herbivores in Taraxacum
}

Received: 22 May 2014/ Accepted: 4 February 2015/Published online: 13 February 2015

(C) The Ecological Society of Japan 2015

\begin{abstract}
Plants defense against herbivore damage is achieved through resistance and tolerance, of which resistance is composed of avoidance and antibiosis. Plants have developed various adaptations that facilitate escape from herbivory. We hypothesized that post-anthesis prostrate scapes in Taraxacum is an adaptation for avoidance of capitulum grazing by large herbivores. To test this hypothesis, we divided flowering into the following four stages based on the external appearance of the capitulum: green bud, yellow corolla, brown corolla, and white pappus stages. We conducted an experiment in natural pasture in Mongolia to artificially raise capitula and rosette leaves of $T$. collinum. We measured the natural height of capitula and rosette leaves of the Mongolian pasture and urban species, T. collinum and $T$. ceratophorum, respectively, and of the Japanese rural and exotic urban species, $T$. japonicum and T. officinale, respectively. We investigated natural grazing by livestock in the field of the capitula and rosette leaves of the two Mongolian species. In Mongolia, naturally short capitula at the green bud and brown corolla stages and rosette leaves of $T$. collinum were not grazed. However, artificially raised capitula and rosette leaves of $T$. collinum and the naturally high capitula and leaves of T. ceratophorum were grazed. Short capitulum and leaf height was shown to be effective for avoidance of livestock grazing in Mongolia. In Japan, T. japonicum and
\end{abstract}

N. Fujita $(\bowtie) \cdot$ R. Koda

Research Institute for Humanity and Nature, 457-4 Motoyama,

Kamigamo, Kita-ku, Kyoto 603-8047, Japan

E-mail: fujitanb@ae.auone-net.jp

Tel.: 075-821-6666

Present address:

N. Fujita

Center for Restoration of Regional Nature,

28-5 Koyama-Horiike-cho, Kita-ku, Kyoto 603-8145, Japan

Present address:

R. Koda

Research Institute of Environment, Agriculture and Fisheries,

Osaka Prefecture, 442, Shakudo, Habikino, Osaka 583-0862, Japan
T. officinale showed similar scape behavior to $T$. collinum and T. ceratophorum, respectively. We discuss the reasons for the capitulum behavior differences in Japan.

Keywords Scape - Livestock P Pasture - Rural habitat Urban habitat

\section{Introduction}

Plant defense against herbivores through tolerance and resistance may involve a combination of defensive strategies (Milchunas and Noy-Meir 2002; Núñez-Farfánet et al. 2007; Fornoni 2011). Although tolerance of herbivore damage reduces the fitness consequences through post-damage regrowth and reproduction (Briske 1991; Strauss and Agrawal 1999; Díaz et al. 2001; Cingolani et al. 2005; Evju et al. 2009), plant resistance reduces the extent of herbivore damage (Tiffin 2000). Resistance can be divided into antibiosis, which reduces herbivore performance, and avoidance, which allows plants to escape from herbivory.

Herbivores are diverse in size and eating habit. The avoidance strategies of plants may vary based on the type of herbivore. Plant avoidance of herbivory by terrestrial mammals is classified into external avoidance (e.g., taking refuge and hiding) and internal avoidance, which includes spatial and temporal tactics (e.g., mimicry) as well as chemical strategies (Milchunas and Noy-Meir 2002). However, unlike antibiosis, disentangling avoidance mechanisms remains a major challenge.

The scapes of Taraxacum species exhibit a gravitropic response (Clifford and Oxlade 1991). In Japan, it is well known that in native Japanese Taraxacum species in rural habitats (Ogawa and Mototani 1991), the scape actively changes from erect at anthesis to prostrate after flowering, and subsequently stands erect prior to achene dispersal (Hirayama 1972). However, it is not known whether scape movement is adaptive. 
In Mongolia, we observed many species of Taraxacum that exhibited prostrate scapes post-anthesis in the steppe, which is similar to native Japanese Taraxacum species. However, within the city of Ulan Bator, we observed that the scapes of urban Taraxacum species did not become prostrate after flowering. If post-anthesis a prostrate scape is adaptive, it may be beneficial in the steppe but not in an urban environment. One of the main habitat differences between the Mongolian steppe and the city is the respective presence and absence of grazing pressure from livestock, because livestock graze pasture plants widely in the steppe because of pastoral nomadism (FernándezGiménez 1999). Hence, Taraxacum species inhabiting rural areas may be exposed to grazing pressure. Unless there is a shortage of forage, livestock do not graze pasture plants close to the soil surface but rather at a height of several centimeters (Fujita et al. 2013a, b). A short plant height is advantageous to reduce grazing pressure from large herbivores (Mitchley 1988; Díaz et al. 2001; Evju et al. 2009). Therefore, plants may avoid livestock grazing by adopting a prostrate habit. In an urban environment, a prostrate habit has no selective advantage because grazing pressure from livestock is absent. Thus, we predict that plants growing in urban and rural locations will show differences in growth habit. In Japan, exotic Taraxacum species occur in urban habitats, whereas endemic Japanese species grow in rural habitats (Ogawa and Mototani 1991). Therefore, the scape behavior of Taraxacum plants may differ between urban and rural environments.

We hypothesized that the post-anthesis prostrate scape in Taraxacum is an adaptation for avoidance of grazing of the capitulum by large herbivores. In order to clarify the relationship between plants and large herbivores, plant palatability and the degree of grazing pressure by large herbivores must be considered. Regarding grazing avoidance, the leaves must also be considered because Taraxacum species that avoid large herbivore grazing may have short scapes and leaves. In contrast, a Taraxacum species with a capitulum borne on a tall, erect scape at anthesis and achene maturity for pollination and wind dispersal of the achenes, respectively (Sheldon and Burrows 1973), may not be grazed. In the city, where grazing pressure by large herbivores is not assumed, short scapes and leaves may be unnecessary for avoidance of grazing pressure.

To test this hypothesis, we gathered field observations and experimental data for Taraxacum in Mongolia and Japan. We first performed an experiment to assess the effect of capitulum and rosette leaf height of a pasture species in Mongolia on susceptibility to livestock grazing. Second, we measured the heights of capitula during the flowering period and of rosette leaves in the field to ascertain height differences between Mongolian pasture and urban species, and between Japanese rural and exotic urban species. Third, we determined whether the capitula and rosette leaves of Taraxacum were grazed under natural field conditions in Mongolia. Last, we measured daily changes in capitulum height from the flower bud stage to the achene dispersal stage in a native
Japanese species to ascertain the dynamic movement of scapes over the course of capitulum development.

\section{Methods}

\section{Study species and sites}

To measure the heights of capitula and leaves of Taraxacum in the Mongolian steppe, we selected Taraxacum collinum DC., which occurs in a relatively dry habitat for a pasture species. We studied a population growing at a small, level site on the northern slope of Mt. Bogd Khan in Ulan Bator [ca. $1630 \mathrm{~m}$ above sea level (asl), 47 $\left.51^{\prime} 43^{\prime \prime} \mathrm{N}, 106^{\circ} 51^{\prime} 41^{\prime \prime} \mathrm{E}\right]$ that was frequently exposed to sheep and goat grazing. For the Mongolian urban-dwelling species, we selected a roadside population of Taraxacum ceratophorum (Ledeb.) DC. near Songiin in Ulan Bator (ca. $1240 \mathrm{~m}$ asl, $47^{\circ} 50^{\prime} 57^{\prime \prime} \mathrm{N}$, $106^{\circ} 40^{\prime} 35^{\prime \prime} \mathrm{E}$ ) where livestock from the adjacent pasture sometimes visited. In Japan, we selected Taraxacum japonicum Koidz. and Taraxacum officinale F.H.Wigg. as rural and exotic urban species, respectively. The study sites of $T$. japonicum and $T$. officinale were ridges between rice fields in Hirano, Otsu (ca. $101 \mathrm{~m}$ asl, $34^{\circ} 57^{\prime} 24^{\prime \prime} \mathrm{N}, 135^{\circ} 57^{\prime} 22^{\prime \prime} \mathrm{E}$ ), and roadsides in Aoyama, Otsu (ca. $145 \mathrm{~m}$ asl, $34^{\circ} 58^{\prime} 31^{\prime \prime} \mathrm{N}, 135^{\circ} 58^{\prime} 11^{\prime \prime} \mathrm{E}$ ), respectively. Natural hybridization in Taraxacum between native sexual diploids and introduced agamospermous triploids occurs in Japan (Watanabe et al. 1997; Shibaike et al. 2002), and T. japonicum hybridizes with $T$. officinale (Takakura et al. 2009). We identified the urban population as $T$. officinale based on the presence of recurved involucral bracts and brown achenes, in addition to the urban environment. To monitor capitulum height continuously throughout flowering, we cultivated a population of $T$. japonicum in an experimental garden at the Center for Ecological Research (CER), Kyoto University, Hirano-cho, Otsu, Japan (ca. $143 \mathrm{~m}$ asl, $34^{\circ} 58^{\prime} 15^{\prime \prime} \mathrm{N}, 135^{\circ} 57^{\prime} 25^{\prime \prime} \mathrm{E}$ ). This population was transplanted from the same population at Hirano, Ohtsu, used for height measurement.

\section{Measurement of capitulum and leaf height}

We measured capitulum height vertically along the scape from the soil surface using a ruler. To determine the length and inclination of the scape, we also measured the horizontal distance from the capitulum to the center of the rosette. To relate scape movement to the flowering stage, we divided the flowering period into the following four stages based on the external appearance of the capitulum and recorded each stage at the time of capitulum height measurement. (1) Green bud stage: the florets were concealed by the green involucral bracts before anthesis. (2) Yellow corolla stage: yellow ligulate florets were visible at times of not only corolla open but also corolla closing before and after the opening. (3) Brown corolla stage: 
corolla withered and turned brown after anthesis. (4) White pappus stage: white pappus bristles were conspicuous before achene dispersal. Each scape bore a terminal capitulum, and an individual rhizome often produced multiple scapes and capitula at different flowering stages. We measured all capitula on each rhizome. The number of scapes measured at the green bud, yellow corolla, brown corolla, and white pappus stages for each species was as follows, and the rhizome number is shown in parentheses: T. collinum: 30 (30), 49 (45), 30 (30), 40 (40); T. ceratophorum: 25 (20), 41 (27), 25 (21), 21 (17); T. japonicum: 21 (15), 23 (18), 23 (19), 20 (16); T. officinale: 20 (19), 35 (26), 20 (15), 20 (15).

For leaf height, we measured the maximum height of the leaf top among the rosette leaves on each rhizome. We also measured the horizontal distance from the leaf top to the center of the rhizome to determine the length and inclination of the leaf. To avoid the possible effect of light competition among plants on leaf height, we only measured leaf height on solitary rhizomes that grew in isolation from other plants. The number of rhizomes measured for each species was 30 for $T$. collinum, 32 for $T$. ceratophorum, 30 for T. japonicum, and 31 for $T$. officinale.

Capitula and leaves were measured on the same dates, namely 2 June 2003, 5 June 2003, 27 April 2005, and 28 April 2005 for T. collinum, T. ceratophorum, $T$. japonicum, and $T$. officinale, respectively. We recorded all measurements in the morning.

Livestock grazing of capitula and leaves

In Mongolia we marked the height-measured capitula and leaves for $T$. collinum and T. ceratophorum at the time of measurement. In the afternoon of the day following the marking, we checked for signs of livestock grazing on the capitula and leaves. The torn capitula and leaves of grazed plants were easily detected, and plants that had been grazed were recorded.

\section{Artificial raising of capitula and leaves}

For T. collinum growing on the northern slope of Mt. Bogd Khan in Mongolia, we artificially raised prostrate capitula (at the green bud and brown corolla stages) and rosette leaves in the same population used for height measurement. On the morning of 2 June 2003, we placed a wooden toothpick $(1.8 \mathrm{~mm}$ in diameter and $6.5 \mathrm{~cm}$ in length) into the soil near the rhizome and raised the scape or leaf by tying it to the top of the toothpick with a thin thread. We used different rhizomes for capitula and leaves. After treatment we measured the height of the raised capitula and leaves, and checked for signs of livestock grazing on the raised capitula and leaves the following day. The number of raised capitula at the green bud and brown corolla stages, and number of raised leaves was 30 in each instance.
Monitoring of scape movement during flowering

On 27 April 2005, we transplanted plants of T. japonicum to the experimental garden of CER from Hirano. From 13 April 2006 (when the flower bud had developed) to 2 May (when the achenes dispersed), we measured the height of the same capitulum every day in order to monitor scape movement. We measured three capitula from three rhizomes, and recorded the respective flowering stage at each measurement.

\section{Statistical analyses}

Generalized linear mixed models (GLMM) were used to test the significance of differences in the height, length, and inclination of capitula among the flowering stages in each species. We set the height, length, and inclination of each capitulum as response variables and the flowering stage as the explanatory variable. Differences in the rhizome of each capitulum were set as a random effect term in each GLMM. We used the nlme package for R (Pinheiro et al. 2012) and described the relationship using a Gaussian regression model. For post hoc multiple comparison of each GLMM, we used Tukey's HSD test in the multcomp package for R (Hothorn et al. 2008). To test the significance of differences in the height, length, and inclination of leaves among species, we used a oneway ANOVA and Tukey's HSD test. Significance for all tests was set at $P=0.05$. All statistical analyses in this study were performed using the statistical environment $\mathrm{R}$ 2.15.2 (R Development Core Team 2012).

\section{Results}

Grazing of artificially raised capitula and leaves

The horizontal length and vertical height of the artificially raised capitula and leaves of $T$. collinum before livestock grazing are shown in Fig. 1. Livestock grazed all of the capitula and leaves that were artificially raised. The capitula at the green bud and brown corolla stages, as well as the rosette leaves, were grazed when the height was raised artificially above $3 \mathrm{~cm}$ in pasture in which sheep and goats grazed frequently.

\section{Capitulum height}

Taraxacum collinum, a Mongolian pasture species, exhibited distinct capitulum movement with change in inclination during the flowering period. For example, at the green bud stage, the capitulum was low but became high at the yellow corolla stage. At the brown corolla stage, the capitulum was reduced in height, but was raised upright again at the white pappus stage. Among the four flowering stages, capitulum height and inclination were significantly lower at the green bud and brown 
corolla stages, and were significantly higher at the white pappus stage (Table 1). The height of each capitulum did not exceed $3 \mathrm{~cm}$ at the green bud and brown corolla stages (Fig. 2a). However, in T. ceratophorum, a Mongolian urban species, the capitulum height was comparatively high at the four flowering stages compared with T. collinum (Table 1; Fig. 2b). Moreover, capitulum height did not differ significantly between the yellow and brown corolla stages, and the capitulum was not obviously prostrate at the brown corolla stage.

In a native Japanese rural species, $T$. japonicum, similar to T. collinum, the capitulum was prostrate at the green bud and brown corolla stages, and upright at the yellow corolla and white pappus stages (Fig. 2c). Among the four flowering stages, capitulum height and inclination were significantly lower at the green bud and brown

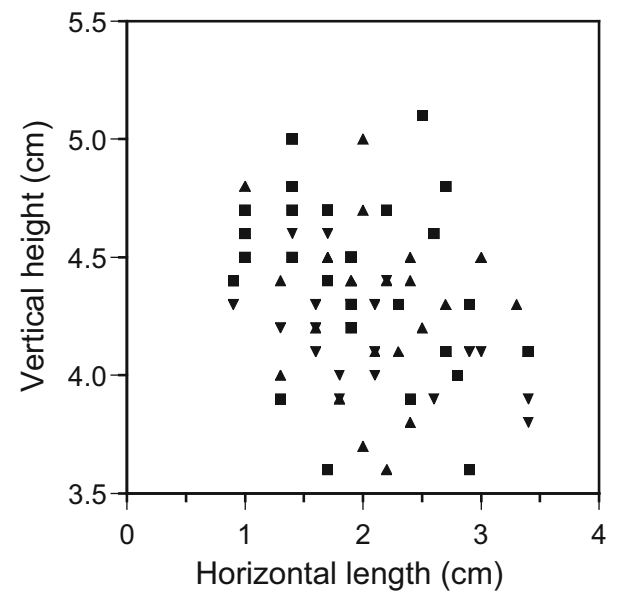

Fig. 1 Horizontal length and vertical height of artificially raised capitula and rosette leaves of Taraxacum collinum before livestock grazing. Upright triangle capitulum at the green bud stage; inverted triangle capitulum at the brown corolla stage; square rosette leaf. Capitula that were grazed and removed by livestock after the capitulum was artificially raised are indicated by black symbols corolla stages, and were significantly higher at the white pappus stage (Table 1), which was consistent with the findings for $T$. collinum. However, a Japanese exotic urban species, T. officinale, similar to T. ceratophorum, did not show distinctly prostrate capitula (height less than $6 \mathrm{~cm}$ ) (Fig. 2d). Furthermore, as with $T$. ceratophorum, no significant difference in capitulum height between the yellow and brown corolla stages was observed.

\section{Leaf height}

Taraxacum collinum (Fig. 3a) and T. japonicum (Fig. 3c) produced leaves of short heights of less than $3 \mathrm{~cm}$ and up to $5 \mathrm{~cm}$, respectively. In contrast, the leaf height in T. ceratophorum (Fig. 3b) and T. officinale (Fig. 3d) was rarely less than 3 and $5 \mathrm{~cm}$, respectively. Among the four species, the mean leaf height was lowest in T. collinum and $T$. japonicum, and was significantly higher in $T$. officinale $(P<0.05)$ (Table 2). The low height of the leaves was due to the gentle leaf inclination in T. japonicum and the short leaf length in T. collinum (Table 2).

\section{Natural livestock grazing}

In $T$. collinum, capitula at the green bud and brown corolla stages, as well as the rosette leaves were not grazed (Figs. 2a, 3a). Moreover, despite the greater height, capitula at the yellow corolla stage were also not grazed. At the white pappus stage, some capitula were grazed, but possibly only after achene dispersal. This conclusion was deduced because we did not observe signs of grazing of the white pappus before achene dispersal. In $T$. ceratophorum, capitula at all flowering stages, except for the yellow corolla stage, and the rosette leaves were grazed (Figs. 2b, 3b).

Table 1 Mean capitulum height, and scape length and inclination of each Taraxacum species at four flowering stages

\begin{tabular}{|c|c|c|c|c|}
\hline Species & Stage & Height $(\mathrm{cm})$ & Length (cm) & Inclination $\left(^{\circ}\right)$ \\
\hline \multirow[t]{4}{*}{ Taraxacum collinum } & Green bud & $1.7 \pm 0.4 \mathrm{a}$ & $4.4 \pm 0.6 \mathrm{a}$ & $23.7 \pm 8.7 \mathrm{a}$ \\
\hline & Yellow corolla & $4.1 \pm 0.6 \mathrm{~b}$ & $4.7 \pm 0.3 b$ & $65.2 \pm 14.7 b$ \\
\hline & Brown corolla & $2.0 \pm 0.4 \mathrm{a}$ & $4.6 \pm 0.3 \mathrm{ab}$ & $25.6 \pm 6.1 \mathrm{a}$ \\
\hline & White pappus & $5.1 \pm 0.5 \mathrm{c}$ & $5.2 \pm 0.5 \mathrm{c}$ & $80.1 \pm 6.9 c$ \\
\hline \multirow{4}{*}{ T. ceratophorum } & Green bud & $6.4 \pm 2.3 \mathrm{a}$ & $9.9 \pm 2.3 \mathrm{a}$ & $41.6 \pm 12.5 \mathrm{a}$ \\
\hline & Yellow corolla & $11.8 \pm 3.8 b$ & $16.0 \pm 2.9 \mathrm{~b}$ & $51.6 \pm 18.8 \mathrm{~b}$ \\
\hline & Brown corolla & $10.5 \pm 1.9 \mathrm{~b}$ & $19.3 \pm 1.9 \mathrm{c}$ & $33.9 \pm 14.8 \mathrm{a}$ \\
\hline & White pappus & $18.7 \pm 1.7 \mathrm{c}$ & $19.9 \pm 2.2 \mathrm{c}$ & $72.8 \pm 8.8 \mathrm{c}$ \\
\hline \multirow[t]{4}{*}{ T. japonicum } & Green bud & $3.4 \pm 1.2 \mathrm{a}$ & $9.7 \pm 2.7 \mathrm{a}$ & $21.9 \pm 9.0 \mathrm{a}$ \\
\hline & Yellow corolla & $8.8 \pm 2.0 \mathrm{~b}$ & $12.2 \pm 1.9 b$ & $46.6 \pm 8.2 b$ \\
\hline & Brown corolla & $4.0 \pm 1.1 \mathrm{a}$ & $14.3 \pm 2.3 c$ & $16.3 \pm 4.1 \mathrm{a}$ \\
\hline & White pappus & $15.5 \pm 3.0 \mathrm{c}$ & $16.8 \pm 2.8 \mathrm{~d}$ & $69.5 \pm 10.1 \mathrm{c}$ \\
\hline \multirow{4}{*}{ T. officinale } & Green bud & $18.0 \pm 7.5 \mathrm{a}$ & $19.4 \pm 8.0 \mathrm{a}$ & $71.9 \pm 11.6 b c$ \\
\hline & Yellow corolla & $24.7 \pm 4.5 b$ & $26.6 \pm 4.2 b$ & $71.2 \pm 11.4 \mathrm{~b}$ \\
\hline & Brown corolla & $22.1 \pm 5.5 \mathrm{ab}$ & $28.7 \pm 3.5 b$ & $53.8 \pm 17.0 \mathrm{a}$ \\
\hline & White pappus & $35.2 \pm 5.3 c$ & $35.9 \pm 5.3 c$ & $80.8 \pm 7.4 c$ \\
\hline
\end{tabular}

Values are the mean \pm standard deviation

Values with different letters for each species and trait are significantly different among the four stages (generalized linear mixed models and Tukey's HSD tests: $P<0.05$ ) 

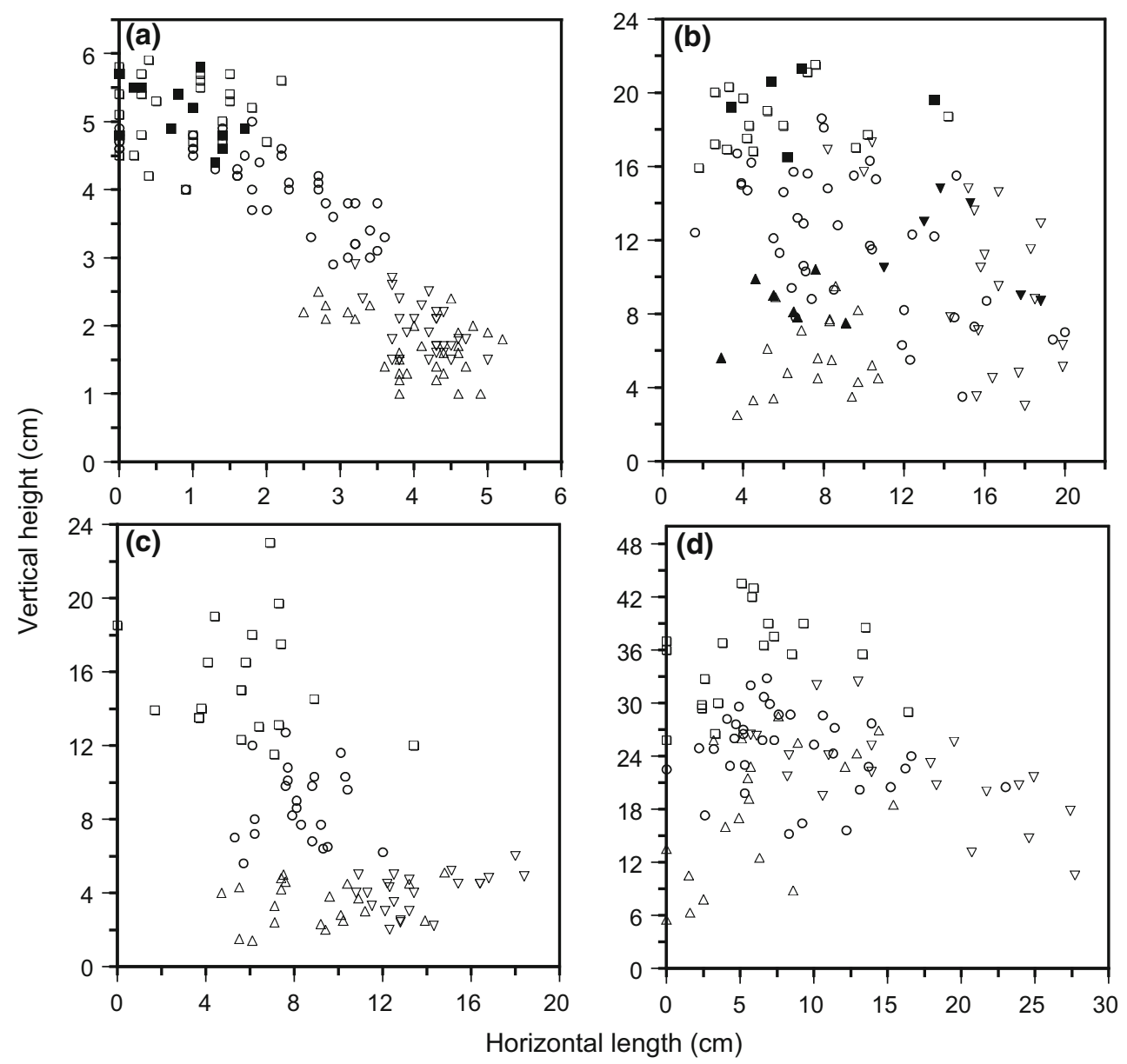

Fig. 2 Horizontal length and vertical height of capitula. a Taraxacum collinum, b $T$. ceratophorum, c $T$. japonicum, d $T$. officinale. Upright triangle capitulum at the green bud stage; circle capitulum

\section{Capitulum movement during flowering}

The height of $T$. japonicum capitula during the flowering is shown in Fig. 4. It was low $(<6 \mathrm{~cm})$ at the green bud and brown corolla stages, while it was high $(>7 \mathrm{~cm})$ at the yellow corolla stage. The capitula at the white pappus stage became high $(>7 \mathrm{~cm})$ again. At the end of the white pappus stage when achene was dispersed, the capitulum became the highest uprightly. The lying and raising of the capitulum occurred after the yellow and brown corolla steage, respectively.

\section{Discussion}

Confirmation of the hypothesis

In Mongolia, the pasture species T. collinum bore capitula at the brown corolla stage (post-anthesis) that were sufficiently prostrate to avoid livestock grazing. However, all capitula of $T$. collinum at the brown corolla stage were grazed when artificially raised. Capitula at the green bud stage and the rosette leaves of $T$. collinum were also prostrate. This strategy was indicated to be at the yellow corolla stage; inverted triangle capitulum at the brown corolla stage; square capitulum at the white pappus stage. Grazed capitula are indicated by black symbols

effective for avoidance of livestock grazing, because all were grazed when artificially raised. In the forest steppe zone of Mongolia, the grazing height of small and large livestock is almost 3 and $5 \mathrm{~cm}$, respectively (Fujita et al. 2013a). On the northern slope of Mt. Bogd Khan, where the $T$. collinum population used in this study was located, a height of less than $3 \mathrm{~cm}$ was sufficient to avoid grazing for $T$. collinum, since sheep and goats were the main nomadic livestock. However, the urban species $T$. ceratophorum maintained raised capitula at the green bud and brown corolla stages as well as rosette leaves of increased height, which made them susceptible to livestock grazing. Thus, if livestock entered the city environment, the capitula and leaves were grazed. However, livestock grazing was rare in the urban environment. Therefore, the present results supported the hypothesis that post-anthesis prostrate scapes of Taraxacum is an adaptation for avoidance of grazing of the capitula by large herbivores.

That the capitulum becomes prostrate after anthesis in Taraxacum is well known (Hirayama 1972). In addition, we observed that $T$. collinum capitula at the green bud stage were also prostrate. Capitula of $T$. collinum at the green bud stage were indicated to be palatable to 


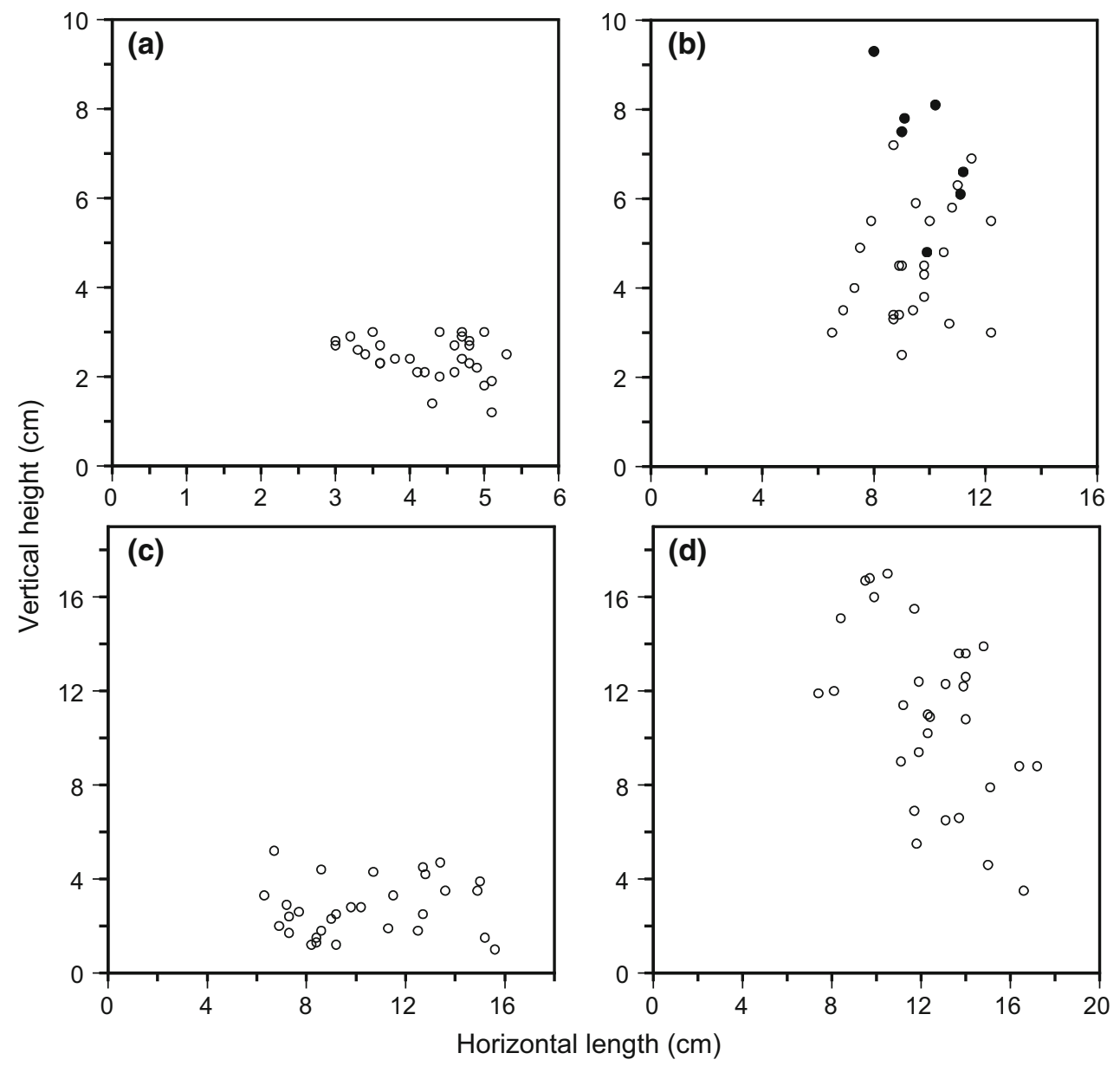

Fig. 3 Horizontal length and vertical height of the tip of the tallest rosette leaf. a Taraxacum collinum, b T. ceratophorum, c T. japonicum, d T. officinale. Grazed leaves are indicated by black symbols

Table 2 Mean leaf traits for each Taraxacum species

\begin{tabular}{lrrr}
\hline Species & Height $(\mathrm{cm})$ & Length $(\mathrm{cm})$ & Inclination $\left({ }^{\circ}\right)$ \\
\hline Taraxacum collinum & $2.4 \pm 0.5 \mathrm{a}$ & $4.9 \pm 0.6 \mathrm{a}$ & $30.1 \pm 7.3 \mathrm{~b}$ \\
T. ceratophorum & $5.1 \pm 1.7 \mathrm{~b}$ & $10.9 \pm 1.7 \mathrm{~b}$ & $27.9 \pm 7.9 \mathrm{~b}$ \\
T. japonicum & $2.8 \pm 1.2 \mathrm{a}$ & $10.8 \pm 2.8 \mathrm{~b}$ & $15.4 \pm 7.1 \mathrm{a}$ \\
T. officinale & $11.1 \pm 6.6 \mathrm{c}$ & $17.1 \pm 2.1 \mathrm{c}$ & $41.0 \pm 13.2 \mathrm{c}$ \\
\hline
\end{tabular}

Values are the mean \pm standard deviation

Values with different letters for each trait are significantly different among species (one-way ANOVA and Tukey's HSD tests: $P<0.05)$

livestock based on the results of the artificial raising experiment, becoming prostrate at both the green bud and brown corolla stages may be a grazing avoidance strategy.

\section{Significance of capitulum raising}

The Mongolian pasture species $T$. collinum raised the capitula twice, from the green bud stage to the yellow corolla stage and from the brown corolla stage to the white pappus stage. Although it might require effort to raise the capitulum before flowering and achene dispersal, such movements are considered adaptive. Capitula of diploid Taraxacum species are entomophilous and pollinated at the yellow corolla stage (Totland 1993). Wind dispersal of the achenes occurs at the white pappus stage (Sheldon and Burrows 1973). In the case of insect pollination, it is generally accepted that pollinator insects locate flowers more easily at greater flower heights (Hainsworth et al. 1984; Donnelly et al. 1998; Ågren et al. 2006; Dickson and Petit 2006). With respect to seed dispersal, a higher point of release increases the potential dispersal distance (Okubo and Levin 1989; van Dorp et al. 1996; Nathan et al. 2002; Soons et al. 2004; Thomson et al. 2011). Therefore, the presence of higher capitula is advantageous for pollination and achene dispersal. There is a tendency for the capitulum to be higher at the achene dispersal stage than at anthesis. Thus, capitulum height may be more important for wind dispersal. However, in the case of the agamospermous Japanese exotic species, T. officinale (Richards 1970; Morita et al. 1990), the capitulum height is comparatively high throughout flowering.

The capitula of Mongolian pasture and urban species were not grazed by livestock in spite of the elevated 

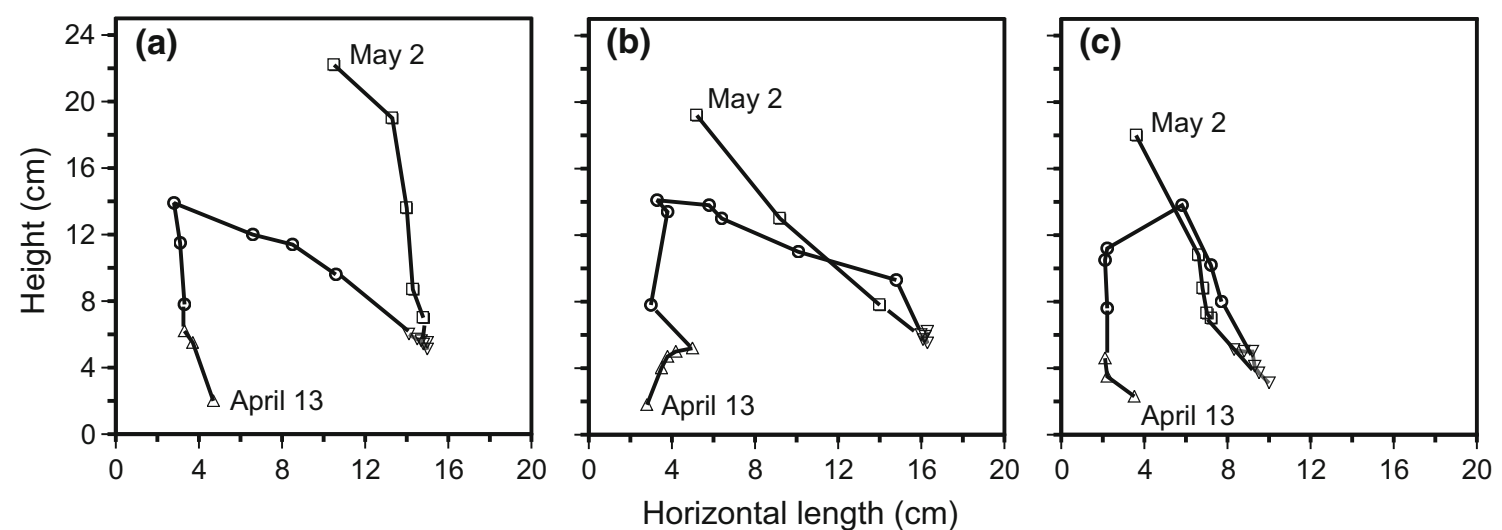

Fig. 4 Daily movement of three individual capitula from different rhizomes of Taraxacum japonicum from bud appearance to achene dispersal. Upright triangle capitulum at the green bud stage; circle capitulum at the yellow corolla stage; inverted triangle capitulum at the brown corolla stage; square capitulum at the white pappus stage

height. The corolla of Compositae contains bitter chemicals (Rees and Harborne 1985; Hattori et al. 1992), and therefore livestock seem to be discouraged from grazing because of the unpleasant taste (Launchbaugh and Provenza 1993). Therefore, capitula at the yellow corolla stage were indicated to be resistant to grazing by livestock. Cattle can recognize the yellow color (Thines and Soffis 1977; Dabrowska et al. 1981; Gilbert and Arave 1986) and may associate unpleasant taste with yellow-colored flowers (Thines and Soffis 1977). This is because livestock also avoid grazing on closed yellow corollas before and after flowering in addition to open yellow corollas at the flowering time. We observed that cattle, sheep, and goats rarely spat out bud-stage capitula that appeared green but contained fully developed yellow florets. This observation suggests that livestock graze capitula based on the external color and dislike the taste of yellow florets at anthesis.

\section{Significance of prostrate rosette leaves}

Taraxacum is a forb with rhizomes and rosette leaves. The rosette leaf serves a number of ecological functions. In temperate zones, the rosette leaf is an overwintering organ that photosynthesizes from autumn until spring (Regehr and Bazzaz 1976; Zotz et al. 2000). Taraxacum species that grow in Japan also have overwintering rosette leaves. However, in Mongolia, Taraxacum species lose the rosette leaves over the cold winter; therefore, their function is not overwintering. Although rosette leaves that are borne directly from the rhizome are disadvantageous for light competition with cauline leaves (Carlassare and Karsten 2003), rosette leaves can be produced at a lower height than cauline leaves. The dominance of rosette plants increases in sites grazed by large herbivores (Noy-Meir et al. 1989; Díaz et al. 1992; Lavorel et al. 1999). Grasses and forbs show different responses to grazing by large herbivores. For example, grasses that have a growing point at the leaf base (intercalary meristem) can endure grazing and give rise to short, grazed lawns (Hunter 1962; Bakker et al. 1983; McNaughton 1984). However, forbs with rosette leaves, including Taraxacum, can provide low ground cover but incur damage from grazing. The avoidance of livestock grazing is doubly advantageous for forbs, resulting in the exclusion of taller light-competitors. The gentle leaf inclination in $T$. japonicum is effective at maintaining a low plant height, as is the short leaf length in T. collinum.

If sheep and goats become very hungry, they may graze on the aboveground shoots and belowground rhizomes of herbs (Fujita et al. 2013b). Livestock in the steppe and dry steppe zones are often hungry because of lower annual and seasonal pasture production compared with the forest steppe zone (Fujita et al. 2013a). Therefore, even prostrate plants may struggle to avoid livestock grazing in the steppe and dry steppe zones.

\section{Lying in Japanese species}

In Japan, T. japonicum (Japanese rural species) and $T$. officinale (Japanese exotic urban species) showed similar capitulum movements and similar rosette leaf height to T. collinum (Mongolian pasture species) and T. ceratophorum (Mongolian urban species), respectively. However, the prostrate height of $T$. japonicum was less than $6 \mathrm{~cm}$, which was higher than that of $T$. collinum. In Japan, the habitat of Japanese native species has not been grazed by livestock in recent years. Thus, two historical explanations may account for the prostrate behavior observed in $T$. japonicum, namely phylogenetic constraint (McKitric 1993) or evolutionary acquisition (Agrawal 2011). Taraxacum japonicum is closely related to T. mongolicum Hand.-Mazz. (Morita 1995), which is a pasture species in Mongolia. If T. japonicum is derived from a pasture species from continental Asia, the prostrate behavior might be an ancestral trait that has persisted in the T. japonicum lineage. Taraxacum japonicum grows on ridges between rice paddy fields in Hirano, a study site in the present investigation. These ridges have 
historically been disturbed by livestock grazing (Kono 2009) and human mowing and fire (Uematsu et al. 2010). Large livestock, particularly cattle, were used in farming in Western Japan until several decades ago (Kono 2009). Grazing pressure by large livestock may have been exerted on the ridges at that time. Therefore, a height of less than $6 \mathrm{~cm}$ may be an adaptive response to the height of cattle grazing (Sala et al. 1986; Fujita et al. 2013a). We observed that $T$. japonicum is restricted to ridges where mowing and fire continue in spring after Taraxacum flowering every year in Hirano. Therefore, the low height of scapes and rosette leaves in T. japonicum might have originated as an adaptation to cattle grazing or to human mowing and fire.

Acknowledgments We are grateful to Dr. R. Tsujino and Dr. T. Seyama for their helpful suggestions and comments. This study was financially supported in part by the research project "Collapse and Restoration of Ecosystem Networks with Human Activity" of the Research Institute for Humanity and Nature, by the 21st Century Center of Excellence program of the Center for Ecological Research, Kyoto University, and by JSPS KAKENHI Grant Number 26850106.

\section{References}

Agrawal AA (2011) Current trends in the evolutionary ecology of plant defence. Funct Ecol 25:420-432

Agren J, Fortunel C, Ehrlén J (2006) Selection on floral display in insect-pollinated Primula farinosa: effects of vegetation height and litter accumulation. Oecologia 150:225-232

Bakker JP, de Leeuw J, van Wieren SE (1983) Micro-patterns in grassland vegetation created and sustained by sheep-grazing. Vegetatio 55:153-161

Briske DD (1991) Developmental morphology and physiology of grasses. In: Heitschmidt RK, Stuth JW (eds) Grazing management: an ecological perspective. Timber Press, Portland, pp 85-108

Carlassare M, Karsten HD (2003) Species population dynamics in a mixed pasture under two rotational sward grazing height regimes. Agron J 95:844-854

Cingolani AM, Posse G, Collantes MB (2005) Plant functional traits, herbivore selectivity and response to sheep grazing in Patagonian steppe grasslands. J Appl Ecol 42:50-59

Clifford PE, Oxlade EL (1991) Using dandelion flower stalks for gravitropic studies. Am Biol Teach 53:290-293

Dabrowska B, Harmata W, Lenkiewicz Z, Schiffer Z, Wojtusiak RJ (1981) Color perception in cows. Behav Process 6:1-10

Díaz S, Acosta A, Cabido M (1992) Morphological analysis of herbaceous communities under different grazing regimes. J Veg Sci 3:689-696

Díaz S, Noy-Meir I, Cabido M (2001) Can grazing response of herbaceous plants be predicted from simple vegetative traits? J Appl Ecol 38:497-508

Dickson CR, Petit S (2006) Effect of individual height and labellum colour on the pollination of Caladenia (syn. Arachnorchis) behrii (Orchidaceae) in the northern Adelaide region, South Australia. Plant Syst Evol 262:65-74

Donnelly SE, Lortie CJ, Aarssen LW (1998) Pollination in Verbascum thapsus (Scrophulariaceae): the advantage of being tall. Am J Bot 85:1618-1625

Evju M, Austrheim G, Halvorsen R, Mysterud A (2009) Grazing responses in herbs in relation to herbivore selectivity and plant traits in an alpine ecosystem. Oecologia 161:77-85

Fernández-Giménez ME (1999) Sustaining the steppes: a geographical history of pastoral land use in Mongolia. Geogr Rev 89:315-342
Fornoni J (2011) Ecological and evolutionary implications of plant tolerance to herbivory. Funct Ecol 25:399-407

Fujita N, Amartuvshin N, Ariunbold E (2013a) Annual production and species diversity of Mongolian pasture plants in relation to grazing pressure by livestock. In: Yamamura N, Fujita N, Maekawa A (eds) The Mongolian ecosystem network. Springer, Tokyo, pp 131-143

Fujita N, Amartuvshin N, Ariunbold E (2013b) Vegetation interactions for the better understanding of a Mongolian ecosystem network. In: Yamamura N, Fujita N, Maekawa A (eds) The Mongolian ecosystem network. Springer, Tokyo, pp 157-184

Gilbert BJ, Arave CW (1986) Ability of cattle to distinguish among different wavelengths of light. J Dairy Sci 69:825-832

Hainsworth FR, Wolf LL, Mercier T (1984) Pollination and predispersal seed predation: net effects on reproduction and inflorescence characteristics in Ipomopsis aggregata. Oecologia 63:405-409

Hattori M, Xin-Li H, Qing-Ming C, Kawata Y, Tezuka Y, Kikuchi T, Namba T (1992) 6-hydroxykaempferol and its glycosides from Carthamus tinctorius petals. Phytochemistry 31:4001-4004

Hirayama K (1972) The dandelion. Fukuinkan Shoten, Tokyo (in Japanese)

Hothorn T, Bretz F, Westfall P (2008) Simultaneous inference in general parametric models. Biometrical J 50:346-363

Hunter RF (1962) Hill sheep and their pasture: a study of sheep razing in south-east Scotland. J Ecol 50:651-680

Kono M (2009) Farming and cattle and horses. In: Nakazawa K (ed) Japanese history of human and animals 2: animals in history. Yoshikawakobunkan, Tokyo, pp 96-126 (in Japanese)

Launchbaugh KL, Provenza FD (1993) Can plants practice mimicry to avoid grazing by mammalian herivores? Oikos 66:501-504

Lavorel S, McIntyre S, Grigulis K (1999) Plant response to disturbance in a Mediterranean grassland: how many functional groups? J Veg Sci 10:661-672

McKitric MC (1993) Phylogenetic constraint in evolutionary theory: has it any explanatory power? Annu Rev Ecol Syst 24:307-330

McNaughton SJ (1984) Grazing lawns: animals in herds, plant form, and coevolution. Am Nat 124:863-886

Milchunas DG, Noy-Meir I (2002) Grazing refuges, external avoidance of herbivory and plant diversity. Oikos 99:113-130

Mitchley J (1988) Control of relative abundance of perennial in chalk grassland in southern England. II. Vertical canopy structure. J Ecol 76:341-350

Morita T (1995) Taraxacum. In: Iwatsuki K, Boufford DE, Ohba $\mathrm{H}$ (eds) Flora of Japan vol. 3b Angiospermae, Dicotyledoneae, Sympetalae (b), Hohdensya, Tokyo, pp 7-13

Morita T, Menken SBJ, Sterk AA (1990) The significance of agamospermous triploid pollen donors in the sexual relationships between diploids and triploids in Taraxacum (Compositae). Plant Species Biol 5:167-176

Nathan R, Katul GG, Horn HS, Thomas SM, Oren R, Avissar R, Pacala SW, Levin SA (2002) Mechanisms of long-distance dispersal of seeds by wind. Nature 418:409-413

Noy-Meir I, Gutman M, Kaplan Y (1989) Responses of Mediterranean grassland plants to grazing and protection. $J$ Ecol 77:290-310

Núñez-Farfánet J, Fornoni J, Valverde PL (2007) The evolution of resistance and tolerance to herbivores. Annu Rev Ecol Evol Syst 38:541-566

Ogawa K, Mototani I (1991) Land-use selection by dandelions in the Tokyo metropolitan area, Japan. Ecol Res 6:233-246

Okubo A, Levin SA (1989) A theoretical framework for data analysis of wind dispersal of seeds and pollen. Ecology 70:329-338

Pinheiro J, Bates D, DebRoy S, Sarkar D, R Core Team (2012) nlme: linear and nonlinear mixed effects models. $\mathrm{R}$ package version 3.1-105

R Development Core Team (2012) R: a language and environment for statistical computing. R Foundation for Statistical Computing, Vienna 
Rees SB, Harborne JB (1985) The role of sesquiterpene lactones and phenolics in the chemical defence of the chicory plant. Phytochemistry 24:2225-2231

Regehr DL, Bazzaz FA (1976) Low temperature photosynthesis in successional winter annuals. Ecology 57:1297-1303

Richards AJ (1970) Eutriploid facultative agamospermy in Taraxacum. New Phytol 69:761-774

Sala OE, Oesterheld M, León RJC, Soriano A (1986) Grazing effects upon plant community structure in subhumid grasslands of Argentina. Vegetatio 67:27-32

Sheldon JC, Burrows FM (1973) The dispersal effectiveness of the achene-pappus units of selected Compositae in steady winds with convection. New Phytol 72:665-675

Shibaike H, Akiyama H, Uchiyama S, Kasai K, Morita T (2002) Hybridization between European and Asian dandelion (Taraxacum section Ruderalia and section Mongolica) 2. Natural hybrids in Japan by chloroplast DNA marker. J Plant Res 115:321-328

Soons MB, Heil GW, Nathan R, Katul GG (2004) Determinants of long-distance seed dispersal by wind in grasslands. Ecology 85:3056-3068

Strauss SY, Agrawal AA (1999) The ecology and evolution of plant tolerance to herbivory. Trends Ecol Evol 14:179-185

Takakura K, Nishida T, Matsumoto T, Nishida S (2009) Alien dandelion reduces the seed-set of a native congener through frequency-dependent and one-sided effects. Biol Invasions 11:973-981
Thines G, Soffis M (1977) Preliminary experiments on color-vision in cattle. Br Vet J 133:97-98

Thomson FJ, Moles AT, Auld TD, Kingsford RT (2011) Seed dispersal distance is more strongly correlated with plant height than with plant mass. J Ecol 99:1299-1307

Tiffin P (2000) Are tolerance, avoidance and antibiosis evolutionally and ecologically equivalent responses of plants to herbivores? Am Nat 155:128-138

Totland Ø (1993) Pollination in alpine Norway: flowering phenology, insect visitors, and visitation rates in two plant communities. Can J Bot 71:1072-1079

Uematsu Y, Koga T, Mitsuhashi H, Ushimaru A (2010) Abandonment and intensified use of agricultural land decrease habitats of rare herbs in semi-natural grasslands. Agric Ecosyst Environ 135:304-309

van Dorp D, van den Hoek WPM, Daleboudt C (1996) Seed dispersal capacity of six perennial grassland species measured in a wind tunnel at varying wind speed and height. Can $\mathbf{J}$ Bot 74:1956-1963

Watanabe M, Maruyama Y, Serizawa S (1997) Hybridization between native and alien dandelions in the western Tokai district. (1) Frequency and morphological characters of the hybrid between Taraxacum platycarpum and $T$. officinale. J Jpn Bot 72:51-57

Zotz G, Franke M, Woitke M (2000) Leaf phenology and seasonal carbon gain in the invasive plant, Bunias orientalis L. Plant Biol $2: 653-658$ 